\title{
The International Universities Walking Project: Development of a Framework for Workplace Intervention Using the Delphi Technique
}

\author{
Nicholas Gilson, Wendy J. Brown, Guy Faulkner, Jim McKenna, Marie Murphy, \\ Andy Pringle, Karin Proper, Anna Puig-Ribera, and Aphroditi Stathi
}

\begin{abstract}
Background: This paper aimed to use the Delphi technique to develop a consensus framework for a multinational, workplace walking intervention. Methods: Ideas were gathered and ranked from eight recognized and emerging experts in the fields of physical activity and health, from universities in Australia, Canada, England, the Netherlands, Northern Ireland, and Spain. Members of the panel were asked to consider the key characteristics of a successful campus walking intervention. Consensus was reached by an inductive, content analytic approach, conducted through an anonymous, three-round, e-mail process. Results: The resulting framework consisted of three interlinking themes defined as "design, implementation, and evaluation." Top-ranked subitems in these themes included the need to generate research capacity (design), to respond to group needs through different walking approaches (implementation), and to undertake physical activity assessment (evaluation). Themes were set within an underpinning domain, referred to as the "institution" and
\end{abstract}

\footnotetext{
Gilson and Brown are with the School of Human Movement Studies, University of Queensland, Queensland, Australia. Faulkner is with the Faculty of Physical Education and Health, University of Toronto, Toronto, Ontario, Canada. McKenna is with the Carnegie Research Institute, Faculty of Sport and Education, Leeds Metropolitan University, Leeds, UK. Murphy is with the School of Sports Studies, University of Ulster, Ulster, Northern Ireland. Pringle is with the Carnegie Research Institute, Faculty of Sport and Education, Leeds Metropolitan University, Headingly Campus, Leeds, UK. Proper is with EMGO Institute, VU University Medical Centre, Amsterdam, Netherlands. Puig-Ribera is with Llicenciatura de Ciències de l'Activitat Física i l'Esport, Universitat de Vic, Barcelona, Spain. Stathi is with the School for Health, University of Bath, Bath, UK.
}

sites are currently engaging with subitems in this domain, to provide sustainable interventions that reflect the practicalities of local contexts and needs. Conclusions: Findings provide a unique framework for designing, implementing, and evaluating walking projects in universities and highlight the value of adopting the Delphi technique for planning international, multisite health initiatives.

Keywords: consensus, ecological approach, program planning, and physical activity

Physical activity (PA) has been identified as particularly important in countering the development of chronic illnesses, including cardiovascular disease, diabetes, and some cancers. ${ }^{1}$ In adults, participation in at least 30 minutes of moderate-intensity PA, at least five times a week is now widely recognized as the minimal volume associated with health benefits. ${ }^{1-3}$

Walking is an accessible form of PA through which daily recommendations can be achieved ${ }^{4}$ and accumulating 10,000 daily steps has been identified by researchers as an important public health target for adults. ${ }^{5,6}$ Encouraging increased steps among those who are sedentary, even if not achieving the recommendation of 10,000 steps/day, can also be cited as an important goal, with health gains attained as people move from doing no PA to doing some. For example, a recent randomized control trial found significant decreases in systolic blood pressure and waist circumferences in sedentary adults who walked briskly for 30 minutes, three times a week. ${ }^{7}$

Efforts to encourage people to walk more have met with some success at the population level ${ }^{8}$ and within smaller, community settings. ${ }^{9}$ One key setting is the workplace, where many people spend a significant proportion of their week. ${ }^{10}$ Initiatives in educational settings such as universities are particularly desirable, given that they are often among the largest employers in 
cities throughout the world, and as such represent distinct multicultural communities with diverse backgrounds and occupational roles. Furthermore, certain occupational roles in universities may have a predilection for high volumes of sitting, a behavior strongly linked to being overweight or obese. ${ }^{11}$ For example, cross-sectional findings in Australian, English, and Spanish employees have shown sitting times of around five to seven hours/day in academic and administrative staff, with lower levels of sitting linked to high levels of workday walking. ${ }^{12}$

Two recent systematic reviews provide a comprehensive overview of workplace walking ${ }^{13,14}$ and identify two randomized control trials which have aimed to improve walking within the university setting. Purath et al ${ }^{15}$ investigated the impact of health screening, counseling and a telephone call, on the walking behavior of sedentary female university employees in the USA $(n=$ 271). Six-week follow-up measures showed that, compared with a control, intervention participants increased their walking by around 30 minutes/week. Using guidance materials and weekly e-mail reminders, Gilson et $\mathrm{al}^{16}$ showed increases of around 1000 steps/day in UK university employees who undertook either route or incidental walking, over 12 weeks $(n=64)$. Step count increases were linked to small, nonsignificant decreases in blood pressure, ${ }^{16}$ along with self-reported improvements in perceptions of well-being and work productivity. ${ }^{17}$

These findings highlight the positive impact walking programs can have on university employees, yet evidence on how to develop and implement these programs remains limited, with data restricted to small sample sizes and isolated studies. The International Universities Walking Project (IUWP) is a collaborative initiative that aims to address the need for a large sample, multisite study. The project plans to implement walking interventions at universities around the world during academic years 2009-10 - this article describes the intervention framework for the IUWP, developed through the application of a Delphi technique. Formative planning and the development of project frameworks are recognized as essential components of overall program success ${ }^{18}$ and this may be particularly true for large -scale, multisite initiatives such as the IUWP. However, despite this recognition, studies reporting formative developments are relatively rare, with the extant literature dominated by postintervention evaluations.

\section{Methods}

\section{The Delphi Technique}

Named after the location of the ancient Greek oracle, the Delphi technique was developed in the United States (1950-60s) as a means of forecasting the impact of technology on warfare. ${ }^{19}$ It is a mixed-method research approach, designed for the collection and aggregation of informed judgments, relative to a key issue or concept.
Through a series of rounds (usually three), the Delphi provides a consensus framework from a recognized panel of experts. The process begins with an open-ended questionnaire, designed to elicit key items of information. During subsequent rounds, the panel rates the relative importance of each information item, with a view to moving toward consensus in round three.

\section{Rationale for Delphi Selection}

Two factors designated the Delphi technique as the method of choice for framework development. Few studies deal with university settings and even then only within single sites. ${ }^{13,14}$ This lack of available data discounts undertaking either a systematic review or metaanalysis, particularly given that behavior change is considered to be most effective when based around intervention designs that reflect specific behaviors and contexts. $^{20}$ The Delphi represents a viable alternative when the extant literature is weak and expert consultation is becoming an increasingly acceptable source for gathering evidence. ${ }^{21}$

Practical aspects of the technique also suited the project, providing a method through which worldwide partners could effectively interact and develop ownership of a collective, harmonized framework. The Delphi does not depend on "face-to-face" contact, yet is efficient and cost-effective. ${ }^{19,22}$ Feedback provided after each round guides the group toward consensus on a specific issue and provides the opportunity for views and ideas to evolve and be refined. Importantly, the process is anonymous and guided by a facilitator - this counters conformity and dominant personalities while promoting freedom to express personal opinion.

\section{The Delphi Panel and Partner Institutions}

The IUWP involves seven universities from Australia, Canada, England $(n=2)$, the Netherlands, Northern Ireland, and Spain. Participating institutions are major regional universities, based on urban campuses, with a range of 671 to 4655 employees. Each institution is represented by a principal investigator and founding member of the IUWP, who expressed an interest in collaboration, following publication of previous feasibility work at our initial workplace walking site. ${ }^{16}$ The project is coordinated by a lead investigator.

The lead and principal investigators formed the Delphi panel for development of the framework. The panel (5 women and 3 men; age range 34 to 55 years), has widely published within the field of physical activity and health (around 300 peer reviewed papers) and each member holds a doctorate in an associated discipline (range of 4 to 24 years since award). These factors evidence the group's established and emerging expert status and complement a combined total of over 100 years of full-time university employment. Panel membership was deliberately restricted to these key individual experts, given their detailed understanding of walking-based research programs, their overview of the 
key issues at each locality and the need for investigators to develop "ownership" of the intervention.

\section{Procedures and Analyses}

To establish consensus, a three-round conference style format was adopted. During round one, the lead member of the panel distributed an open-ended question to the group via e-mail (March 2007). Members were asked to review the founding aims of the International Universities Walking Project, which were to

- Provide opportunities for university employees to engage in workplace walking.

- Generate high-quality research examining the extent to which walking programs work across a world-wide spectrum of universities.

The panel was then invited to submit an unlimited number of suggestions in response to the following:

There are a number of characteristics you would expect to see included in a successful workplace walking program. With respect to the aims of our partnership, provide a list of the key characteristics (unlimited number) you would incorporate in a multisite, international university walking initiative.

Experts were asked to return their responses to a facilitator external to the Delphi process. The external facilitator replaced respondent names with numbers and then forwarded replies to the lead investigator and a nominated member of the panel. These experts freecoded each panel member's responses separately, identifying common characteristics, through an inductive, content analytic approach. They then met in person and agreed on a preliminary framework.

The preliminary framework formed the basis for a second closed questionnaire distributed to all panel members, via the facilitator. During this second round, panel members were first asked for agreement on the structure of the framework and the need for clarifications/adaptations to the wording of salient subitems; any comments received were forwarded anonymously to the group for review and integration into the framework where appropriate. Following this, members of the expert panel were asked to individually rate the relative importance of the framework's individual subitems, on a 4-point Likert scale ( 1 = not important; 4 = very important). Questionnaires were then returned to the lead investigator via the facilitator, who collated the scores from each panel member.

During the third and final round, questionnaires were redistributed to each individual expert, containing a summary of their score for each subitem, along with the score for the group as a whole. Panel members were invited to review their individual ratings against these group means, and resubmit their responses with changed or unchanged scores. At this point, it was possible to request either a rationale or clarification for scores \pm 2 points from the group mean. Final responses were returned to the facilitator and then the lead investigator, group means for each subitem calculated and items ranked according to their score. This represented the group's consensus framework, distributed via e-mail to the expert panel with summary statistics (May 2007); distribution preceded "face-to-face" project meetings held at two international conferences (May and September 2007), where our final framework was ratified.

\section{Findings and Discussion}

The agreed consensus (Figure 1) identified three interlinking themes, defined as "design, implementation, and evaluation." Themes were set within the context of a domain, described as the "institution" and this domain was viewed as providing the foundation for successful interventions, relative to the local needs and contexts of collaborative sites. Themes and the domain consisted of constituent ranked subitems, describing a range of designated methods and approaches.

\section{Design Theme (Guiding Principles)}

Effective study design is a prerequisite of any successful intervention. ${ }^{18}$ The panel identified this area as a theme with five salient subitems or "guiding principles" (Table 1).

Integrating theory and evidence into study design was considered essential to inform good practice (mean rating of $4.0 \pm 0.0$ ), with effective movement from theoretical design to implementation, dependant on research capacity. Our consensus highlighted the criticality of building research capacity through external funding (mean rating of $4.0 \pm 0.0$ ), which would promote free access and facilitate participant involvement. ${ }^{23}$

Collaboration and proactive problem-solving was recognized as highly important in prioritizing design parameters and funding goals (mean rating of $4.0 \pm 0.0$ ). Developing this type of teamwork is a major strength of the Delphi process ${ }^{19,22}$ and the panel acknowledged the need to maintain this perspective across sites. Our framework also stressed the importance of integrating common methods and procedures into study design (mean rating of $3.9 \pm 0.4$ ) and this included the necessity for back-translation of written materials at nonEnglish language sites.

The final subitem in this theme recognized the need for comprehensive levels of scientific evidence, generated from mixed-method research designs (mean rating of $3.8 \pm 0.5)$. Experimental approaches incorporating randomized controlled trials are widely recognized as providing the strongest type of research evidence. ${ }^{24}$ Complementing this positivist approach, the consensus highlighted the importance of adopting ideographic research strategies and synergizing quantitative and qualitative data, to triangulate research evidence from a variety of sources. 


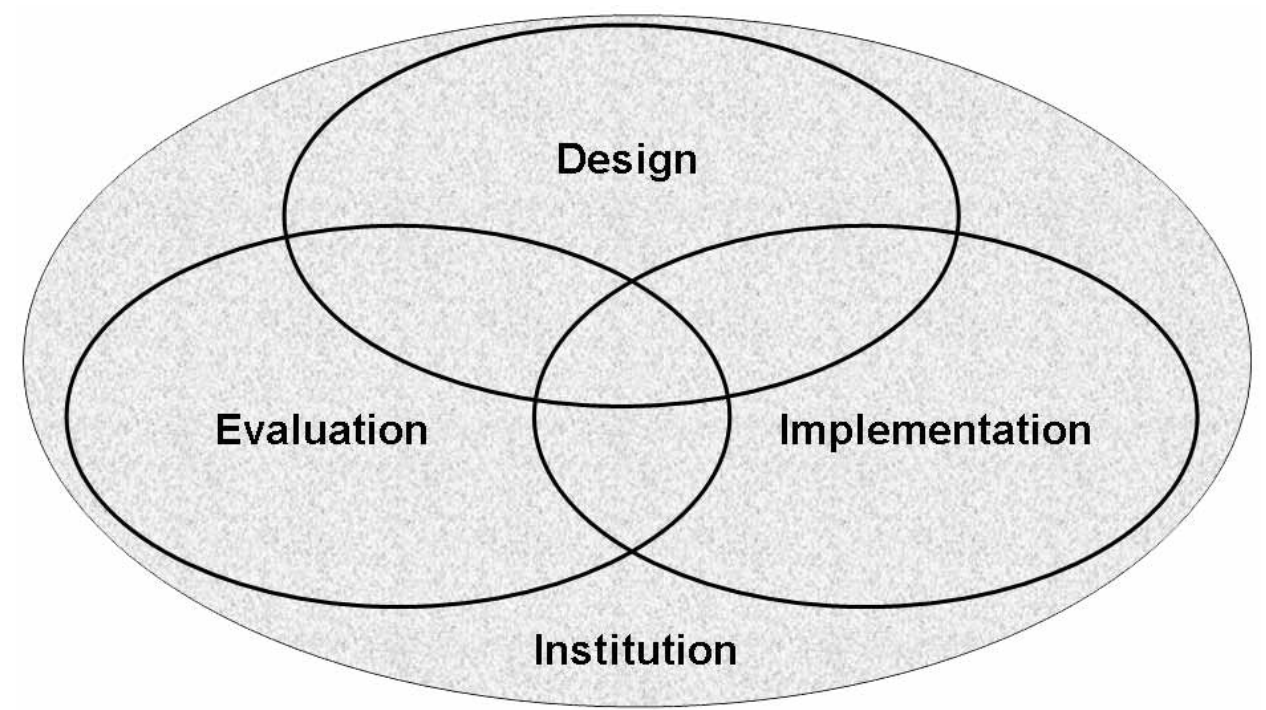

Figure 1 - Consensus framework: Domain (institution) and interlinking themes (design, implementation, and evaluation).

Table 1 Design Theme (Guiding Principles)

\begin{tabular}{|c|c|c|}
\hline Subthemes and descriptors & Mean \pm SD & Rank \\
\hline $\begin{array}{l}\text { Theoretical perspectives and evidence } \\
\text { The initiative tests and generates theory and draws on a strong evidence } \\
\text { base. }\end{array}$ & $4.0 \pm 0.0$ & $1=$ \\
\hline $\begin{array}{l}\text { External funding } \\
\text { Appropriate finance to support free access and build research capacity, such } \\
\text { as strong infra-structure and dedicated time/personnel. }\end{array}$ & $4.0 \pm 0.0$ & $1=$ \\
\hline $\begin{array}{l}\text { Collaboration } \\
\text { Maintain close professional relationships through agreed consensus and } \\
\text { proactive problem solving }\end{array}$ & $4.0 \pm 0.0$ & $1=$ \\
\hline $\begin{array}{l}\text { Standardized methodology } \\
\text { While capturing local cultural differences, the initiative needs to adopt a } \\
\text { standardized approach across sites. This should include back-translation, } \\
\text { equipment and procedures. }\end{array}$ & $3.9 \pm 0.4$ & 4 \\
\hline $\begin{array}{l}\text { Mixed method approach } \\
\text { This should include randomized controlled trails, ideographic research } \\
\text { strategies and triangulation. }\end{array}$ & $3.8 \pm 0.5$ & 5 \\
\hline
\end{tabular}

\section{Implementation Theme (Participant Support)}

Factors that promote recruitment and adherence are important components of sustainable interventions. ${ }^{25}$ Accordingly, the framework recognized "implementation" as a theme within which recruitment and adherence components emerged as "participant support" subitems (Table 2).

The highest ranked subitem within this theme highlighted the value of accounting for participant diversity - such as men and women or the sedentary and more active-through provision of different types of walking (mean rating of $3.9 \pm 0.4$ ). Approaches included access to structured (routes or trails) and unstructured (incidental steps during work tasks) walking opportunities, as well as active transport (walking to and from work). Literature supports how these approaches effectively increase step counts. ${ }^{16,26,27}$

Experiential knowledge, or raising awareness of health status through information, is important in moving people through stages of PA change. ${ }^{28} \mathrm{~A}$ highly rated subitem identified the value of feedback and how data not only informs good practice (through evaluation), but also supports and guides participants in a progressive and sustainable way (mean rating of $3.5 \pm 0.5$ ). Within walking interventions, pedometers represent an excellent source of experiential knowledge, with feedback on step counts acknowledged as an effective motivational strategy. ${ }^{29}$ 
Table 2 Implementation Theme (Participant Support)

\begin{tabular}{lcc}
\hline Subthemes and descriptors & Mean \pm SD & Rank \\
\hline $\begin{array}{l}\text { Group needs and walking opportunities } \\
\text { A variety of walking opportunities should reflect the needs of different }\end{array}$ & $3.9 \pm 0.4$ \\
employees. Approaches should include traditional route-based walking, & \\
along with incidental activities and active transport. & $3.5 \pm 0.5$ \\
Experiential knowledge & \\
$\quad \begin{array}{l}\text { Provision of feedback concerning attainment and progress; to include health } \\
\text { measures, with an emphasis on the use of step counts and goal-setting. }\end{array}$ & $3.1 \pm 0.6$ \\
Virtual support & \\
$\quad \begin{array}{l}\text { Use of the internet and a dedicated website to support social interaction, } \\
\text { guidance materials, emails and weekly logs. }\end{array}$ & $2.4 \pm 0.5$ \\
Educational forums & \\
$\quad$ Lectures, workshops, seminars contribute to experiential knowledge and \\
provide opportunities to share experiences.
\end{tabular}

The panel also highlighted how the process of feedback could be facilitated through guidance materials, weekly logs, and goal setting. Increased access to the internet illustrates that electronic sources have a key role to play in providing this kind of support and guidance. ${ }^{30,31}$ Further to this, a recent systematic review highlights how social support and being able to be active with companions is one of the most powerful factors influencing walking. ${ }^{32}$ The consensus recognized how virtual support through weekly emails and a dedicated website, promotes networks, social interaction and a sense of inclusiveness (mean rating of $3.1 \pm 0.6$ ). Development of this kind of resource is given added impetus by the number and scope of collaborative institutions, with different sites able to access the same resources, tailored to different cultural contexts.

The final two subitems in this major theme concerned the provision of educational forums and the implementation of a reward scheme. Staging of regular lectures, seminars, and workshops, where participants share experiences of benefits and barriers, were viewed as contributing to experiential knowledge and facilitating long-term behavior change (mean rating of $2.4 \pm$ $0.5)$. A reward scheme would remunerate participants for achieving goals through merchandise or purchase subsidies (mean rating of $1.9 \pm 0.8$ ). Reflecting its score as the lowest ranked subitem in the framework, the panel generally regarded this strategy as the least important support and guidance mechanism; while effective at initiating short term change, these types of extrinsic motivators are considered poor initiators of long-term behavior change. ${ }^{33}$

\section{Evaluation Theme (Measures)}

Five subitems or "measures" were embedded in the theme of "evaluation" (Table 3). Measurement of PA was ranked as the most important (mean rating of $3.8 \pm$
0.7), with a valid and reliable pedometer viewed as a practical and inexpensive means of capturing step count frequency. ${ }^{6}$ The panel highlighted the need to use accelerometers in subsamples across sites, to objectively capture the intensity, duration and total energy expenditure associated with walking. ${ }^{34}$

The need to evaluate physical health outcomes was also rated as very important (mean rating of $3.6 \pm 0.7$ ) with key indices including classical epidemiological risk factors for chronic disease, such as body fat, hypertension, and blood metabolites. ${ }^{1}$ It was interesting to note that the framework adopted a wider view of health than that advocated by the scientific, medical model, in that psychosocial measures, such as quality of life and affect, were also considered to be very important (mean rating of $3.4 \pm 1.1$ ); this subitem demonstrated the widest variability in importance. Research has shown the positive impact PA has on sick leave ${ }^{35}$ and work productivity ${ }^{17}$ and that PA interventions can be cost effective. ${ }^{36}$ The consensus recognized the need to quantify and qualify these types of fiscal-orientated factors (mean rating of $3.6 \pm 0.7$ ) and that these outcomes might be critical in enabling and reinforcing institutional support for walking initiatives.

Measurement of inactivity was the final subitem in this theme. Certain types of workers engaged in sedentary tasks have been found to spend a large proportion of their working day sitting ${ }^{37}$ and this behavior has been independently linked to being overweight or obese. ${ }^{38}$ Within this context, measures of inactivity were viewed as complementary to measures of walking (mean rating of $3.1 \pm 0.6)$.

\section{Institution Domain (Roles and Responsibilities)}

The panel identified that the interlinking themes of "design, implementation and evaluation" should be set 
Table 3 Evaluation Theme (Measures)

\begin{tabular}{|c|c|c|}
\hline Subthemes and descriptors & Mean \pm SD & Rank \\
\hline $\begin{array}{l}\text { Physical activity (walking) } \\
\text { Measurement of patterns (and change) in walking behavior at and outside of } \\
\text { work. }\end{array}$ & $3.8 \pm 0.7$ & 1 \\
\hline $\begin{array}{l}\text { Physical health } \\
\text { Measurement of key physical health indices, identified as body mass index, } \\
\text { waist circumference, blood pressure and blood metabolites. }\end{array}$ & $3.6 \pm 0.7$ & $2=$ \\
\hline $\begin{array}{l}\text { Fiscal-orientated indices } \\
\text { Measurement of sick leave, work productivity/satisfaction and cost } \\
\text { effectiveness. }\end{array}$ & $3.6 \pm 0.7$ & $2=$ \\
\hline $\begin{array}{l}\text { Psychosocial health } \\
\text { Measurement of quality of life, social inclusion and affect. }\end{array}$ & $3.4 \pm 1.1$ & 4 \\
\hline $\begin{array}{l}\text { Inactivity } \\
\text { Measurement of sitting times and sedentary behavior at and outside of work. }\end{array}$ & $3.1 \pm 0.6$ & 5 \\
\hline
\end{tabular}

within the wider context of the "institution." This domain consisted of four generic subitems described as "roles and responsibilities" (Table 4).

An organization's policies and procedures play an important role in promoting workplace PA. ${ }^{39}$ Our consensus highlights the need for integration of walking within workplace policy, ranking this subitem as the highest within the "institution" domain (mean rating of $3.5 \pm 0.8$ ). Panelists specifically alluded to university transport policies, highlighting the need for recognition of active transport, using walking routes as part of the journey to and from work, or between different campus sites.

Studies have shown how walk leaders play an important role in retaining and encouraging participants in walking programs..$^{40,41}$ The consensus applies this principal to institutional politics, with identification of the need for "walking champions" able to lobby for university financial support and facilitate the case for walking across committees, disciplines, faculties and universities (mean rating of $3.5 \pm 0.5$ ). The need for representation within estate planning and management highlights the value of this role at policy level, with appropriate physical infrastructure identified as a key institutional responsibility (mean rating of $3.1 \pm 0.4$ ). Provision of trails ${ }^{42}$ and their safety ${ }^{43}$ are practical examples of how campus environments can be developed to facilitate walking and an important element within the project will be an audit of campus "walkability" using a validated audit tool. ${ }^{44}$

The final subitem in this domain identified the importance of institutional fun walks or walking festivals, as part of the university calendar (mean rating of $2.5 \pm 0.5$ ). While some health-orientated cultural festivals $^{45}$ and fun walks ${ }^{46}$ have been found to decrease health-related risk factors and increase PA, a recent paper has outlined the limitations of one-off events in promoting PA. ${ }^{47}$ The consensus stressed that these types of initiatives should be one component of a wider program, aimed at the promoting and maintaining sustained behavior change.

\section{Framework Overview and Future Directions}

Ongoing work is now adding greater detail to our framework as interventions move toward inception; the fact that the consensus established an institutional domain within which themes were set is significant in this process. IUWP partners are prioritizing engagement with those subitems described in institutional roles and responsibilities and comprehensive site audits and consultations have recently been completed, involving a wider, more heterogeneous range of experts in areas such as human resources, information technology and estate management. Data are in turn informing other subitems and the practicalities of design, implementation and evaluation, relative to the cultural and environmental context of a diverse range of sites. Unlike other methods, which tend to produce rigid frameworks and "one size fits all" interventions, these activities exemplify a particular strength of the Delphi, in that it provides structure and direction, while allowing adaptation and flexibility.

The framework therefore represents a consensual starting point for collaborative partners and a generic template for university walking interventions, which colleagues beyond our own partnership may find useful to their own requirements and institutional contexts. Further to this, the consensus is specific to both behavior (walking) and setting (universities) and this specificity is a strength, given the call for ecological, "tailormade" interventions that account for the needs of individuals and communities, as well as the importance of local policies and environments. ${ }^{19,46}$

The extent to which the framework can be applied to other PA and workplace settings is debatable. Themes and the domain are probably applicable, although given the target behavior and institutional setting individual subitems should be applied with caution. For instance, the use of pedometers is very appropriate for measurement of walking and less so for other PA behaviors, while the staging of educational forums and walking 
Table 4 Underpinning Domain: Institution (Roles and Responsibilities)

\begin{tabular}{lcc}
\hline Subthemes and descriptors & Mean \pm SD & Rank \\
\hline Policy & $3.5 \pm 0.8$ & $1=$ \\
The value of walking at work should be recognized and integrated into & \\
university systems, approaches and strategies; management tiers and & $3.5 \pm 0.5$ \\
employees should adopt and promote a "walking culture." & $1=$ \\
Walking champion & \\
Appointment of a proactive champion/figurehead within the institution, & $3.1 \pm 0.4$ \\
responsible for fund raising and arguing the case for walking across & \\
committees, disciplines, faculties and universities. & \\
Physical infrastructure & \\
Develop campus environment to maximize opportunities to promote & \\
walking. This should include involvement in estate planning and an audit of & \\
campus "walkability." & \\
Events & \\
Walking initiatives should reflect and complement the key features of the & \\
annual university calendar. Examples could include staff development & \\
festivals or community and charity events. & \\
\hline
\end{tabular}

festivals are germane for nonprofit institutions focused on academic learning, yet perhaps less applicable for businesses with different mission statements.

This said, the specificity of the framework should not detract from recognition that the Delphi technique represents a highly appropriate method through which other specialized PA intervention frameworks can be developed. Tolley et $\mathrm{al}^{48}$ have used the Delphi as a means of predicting European trends in walking-our study seems to be the first to apply the technique to PA program planning and panel members commented on a process which was efficient, interactive, and effective.

\section{Conclusions}

This article aimed to develop a framework for a multisite, university workplace walking project, through the application of a Delphi technique. Findings highlight the Delphi as a valuable method for intervention planning and development. They also describe a unique, interlinking framework, which provides a generic platform for university walking interventions. Ongoing work as part of the IUWP is now focusing on using the framework to further develop, then implement and evaluate workplace walking, relative to the diverse cultural and environmental needs of our international sites.

\section{References}

1. Department of Health. At Least Five a Week. Evidence on the Impact of Physical Activity and its Relationship to Health. A Report from the Chief Medical Officer. London: Department of Health; 2004.

2. U.S. Department of Health and Human Services. Physical Activity and Health: A Report of the Surgeon General. Atlanta: National Centre for Chronic Disease Prevention and Health Promotion; 1996.
3. Haskell WL, Lee IM, Pate RR, et al. Physical activity and public health: Updated recommendation for adults from the American College of Sports Medicine and the American Heart Association. Med Sci Sports Exerc. 2007;39:1423-1434.

4. Reger-Nash B, Bauman A, Cooper L, Chey C, Simon KJ. Evaluating communitywide walking interventions. Eval Program Plann. 2006;29:251-259.

5. Chan CB, Ryan DAJ, Tudor-Locke C. Health benefits of a pedometer-based physical activity intervention in sedentary workers. Prev Med. 2004;39:1215-1222.

6. Tudor-Locke CE, Myers AM. Methodological considerations for researchers and practitioners using pedometers to measure physical (ambulatory) activity. Res $Q$ Exerc Sport. 2001;72:1-12.

7. Tully MA, Cupples ME, Hart ND, et al. Randomised controlled trial of home-based walking programmes at and below current recommended levels of exercise in sedentary adults. JCEH. 2007;61:778-783.

8. Brown WJ, Mummery K, Eakin E, Schofield G. 10000 Steps Rockhampton: Evaluation of a whole community approach to improving population levels of physical activity. J Phys Act Heal. 2006;3:1-14.

9. Isaacs AJ, Critchley JA, See Tai S, et al. Exercise evaluation randomized trial (EXERT): a randomized trial comparing GP referral for leisure centre-based exercise, community-based walking and advice only. Health Technol Assess. 2007;11:1-18.

10. Department of Health. Choosing Health Making Healthy Choices Easier. London: Department of Health; 2004.

11. Mummery WK, Schofield GM, Steele R, Eakin EG, Brown WJ. Occupational sitting time and overweight and obesity in Australian workers. Am J Prev Med. 2005;29:91-97.

12. Gilson ND, McKenna J, Puig-Ribera A, Brown WJ, Burton N. The International Universities Walking Project. Employee step counts, sitting times and health status. International Journal of Workplace Health Management., in press. 
13. Ogilvie D, Foster CE, Rothnie $\mathrm{H}$, et al. Interventions to promote walking: Systematic review. BMJ. 2007;334:1204 First published May 31 2007.

14. Dugdill L, Brettle A, Hulme C, McCluskey S, Long A. A review of effectiveness of workplace health promotion interventions on physical activity and what works in motivating and changing employees' health behaviour. National Institute of Health and Clinical Effectiveness (NICE), UK. 2007: http://guidance.nice.org.uk/page. aspx $?=449290$.

15. Purath J, Miller AM, McCabe G, Wilbur J. A brief intervention to increase physical activity in sedentary working women. Can J Nurs Res. 2004;36:76-91.

16. Gilson ND, McKenna J, Cooke CB, Brown WJ. Walking towards health in a university community: A feasibility study. Prev Med. 2007;44:167-169.

17. Gilson ND, McKenna J, Cooke CB. Experiences of route and task-based walking in a university community: Qualitative perspectives within a randomized control trial. $J$ Phys Act Heal. 2008;15(Supp1):172-178.

18. Nutbeam D, Bauman A. Evaluation in a Nutshell. A Practical Guide to the Evaluation of Health Promotion Programs. Sydney: McGraw Hill; 2006.

19. Custer RL, Scarcella JA, Stewart BR. The Modified Delphi Technique- A Rotational Modification. Journal of Vocational and Technical Education. 1999; 15. http:// scholar.lib.vt.edu/ejournals/JVTE/v15n2/custer.html (accessed 15 Jan 2008).

20. Sallis JF, Owen N. Ecological models of health behaviour. In: Glanz K, Rimer BK, Lewis FM, eds. Health Behavior and Health Education. Theory, Research and Practice. San Francisco: John Wiley and Sons; 2002.

21. Faulkner G, Taylor A, Ferrence R, Urban S, Selby P. Exercise Science and the Development of EvidenceBased Practice: A 'Better Practices' Framework. Eur J Sport Sci. 2006;6:117-126.

22. Beech B. Go the extra mile- use the Delphi Technique. $J$ Nurs Manag. 1999;7:281-288.

23. Capdevila Ortis L, Ninerola Maymi J, Cruz Feliu J, et al. Exercise motivation in university community members: A behavioural intervention. Psicothema. 2007;19:250255.

24. Gorard S. Quantitative Methods in Social Science. London: Continuum; 2003.

25. Biddle SJH, Mutrie N. Psychology of Physical Activity. Determinants, Wellbeing and Interventions. London: Routledge; 2001.

26. Napolitano MA, Lerch H, Papandonatos G, et al. Worksite and communications-based promotion of a local walking path. J Community Health. 2006;31:326-342.

27. Besser LM, Dannenberg AL. Walking to public transit: Steps to help meet physical activity recommendations. Am J Prev Med. 2005;29:273-280.

28. Marcus BH, Banspach SW, Lefebvre RC, Rossi JS, Carleton RA, Abrams DB. Using the stages of change model to increase the adoption of physical activity among community participants. Am J Health Promot. 1992;6:424429.
29. Merom D, Rissel C, Phongsavan P, et al. Promoting walking with pedometers in the community: The stepby-step trial. Am J Prev Med. 2007;32:290-297.

30. Napolitano MA, Fotheringham M, Tate D. Evaluation of an internet-based physical activity intervention: A Preliminary investigation. Ann Behav Med. 2003;25:92-99.

31. Steele R, Mummery WK, Dwyer T. Using the internet to promote physical activity: a randomized trial of intervention delivery modes. J Phys Act Heal. 2007;4:245-260.

32. Wendel-Vos W, Droomers M, Kremers S, Brug J, van Lenthe F. Potential environmental determinants of physical activity in adults: A systematic review. Obes Rev. 2007;8:425-4.

33. King AC, Friedman R, Marcus B, et al. Harnessing motivational forces in the promotion of physical activity: The Community Health Advice by Telephone (CHAT) project. Health Educ Res. 2002;17:627-636.

34. Esliger DW, Probert A, Gorbor SC, Bryan S, Laviolette M, Tremblay MS. Validity of the Actical accelerometer step-count function. Med Sci Sports Exerc. 2007;39:1200-1204.

35. van Amelsvoort LG, Spigt MG, Swaen GM, Kant I. Leisure time physical activity and sickness absenteeism; a prospective study. Occup Med. 2006;56:210-212.

36. Department of Health. National Evaluation of Local Exercise Action Pilots. London: Crown; 2007.

37. Brown WJ, Gilson ND, McKenna J, Puig Ribera A. The International University Walking Project: A Comparison of step counts and sitting times at different sites. Med Sci Sports Exerc. 2007;39:s327.

38. Proper KI, Cerin E, Owen N, Brown WJ. Sitting time and socio-economic differences in overweight and obesity. Int J Obes. 2007;31:169-176.

39. Plotnikoff RC, Prodaniuk TR, Fein AJ, Milton L. Development of an ecological assessment tool for a workplace physical activity program standard. Health Promot Pract. 2005;6:453-463.

40. Jancey J, Howat P, Lee A, Shilton T, Fisher J, Iredell H. Effective recruitment and retention of older adults in physical activity research: PALS study. Am J Health Behav. 2006;30:626-635.

41. Mena-Bejarano B. Experiences in promoting physical activity. Rev Salud Publica (Bogota). 2006;8:42-56.

42. Granner ML, Sharpe PA, Hutto B, Wilcox S, Addy CL. Perceived individual, social and environmental factors for physical activity and walking. J Phys Act Heal. 2007;4:278-293.

43. Eakin EG, Mummery K, Reeves MM, et al. Correlates of pedometer use: Results from a community-based physical activity intervention trial (10 000 Steps Rockhampton). Int J Behav Nutr Phys Act. 2007;27:31 First published on July $27^{\text {th }}, 2007$.

44. Dannenburg AL, Cramer TW, Gibson CJ. Assessing the walkability of the workplace: A new audit tool. Am J Health Promot. 2005;20:39-44.

45. Stoddard AM, Palombo R, Troped PJ, Sorensen G, Will JC. Cardiovascular disease risk reduction: The Massachusetts WISEWOMEN project. J Womens Health. 2004;13:539-546. 
46. Brownson RC, Hagood L, Lovegreen SL, et al. A multilevel ecological approach to promoting walking in rural communities. Prev Med. 2005;41:837-842.

47. Murphy NM, Bauman A. Mass sporting and physical activity events-are they "bread and circuses" or public health interventions to increase population levels of physical activity? J Phys Act Heal. 2007;4:193-202.
48. Tolley R, Lumsdon L, Bickerstaff K. The future of walking in Europe: a Delphi project to identify expert opinion on future walking scenarios. Transp Policy. 2001;8:307315. 